Inhibitory products obtained by us from egg-white, ovomucin? ${ }^{7}$, allantoic fluid ${ }^{8}$, ovarian cysts $^{8}$, follicular fluid from cows ${ }^{8}$, and cancer fluid ${ }^{8}$, were all found to contain sialic acid. Both the cancer fluid and the contents of one of the cysts showed very strong inhibitory activity, and no other carbohydrate (except hexosamine) was found to be present in appreciable amounts. This might suggest that sialic acid is of fundamental importance for the inhibitory reaction and may bear some relation to the receptor substance of erythrocytes. This suggestion is supported by the fact that a great many materials reported in the literature as containing hæmagglutination inhibitors have also been found to contain sialic acid ; for example, blood serum, some plasma glycoproteins $^{3}$, human tears ${ }^{8}$, cow's milk ${ }^{8}$, epithelial mucins of various origins, human saliva', and meconium ${ }^{9}$. No quantitative relation, however, has been found between the content of sialic acid and the inhibitory activity of the different products examined. Thus a preparation of submaxillary mucin from cattle has a high content of sialic acid but a very low inhibitory activity, whereas allantoic fluid has a low sialic acid content and a high activity. Pure sialic aeid has no activity at all.

It is then evident that if substances giving the characteristic reactions of sialic acid are concerned in the inhibition of virus hæmagglutination, either finer structural differences in the carbohydrate group or the properties of the accompanying protein component must be the determining factors for the inhibitory activity.

It was agreed with Dr. A. Gottschalk, of the Walter and Eliza Hall Institute of Medical Research, Melbourne, who is also investigating the carbohydrate components of the hæmagglutination-inhibiting mucoprotein from urine, to submit to Nature independently but simultaneously a summary of our results.

Institute of Medical Chemistry,

L. ODIN

University of Uppsala,

$$
\text { Sweden. }
$$

June 20.

1 Tamm, I., and Horsfall, F. L., Proc. Soc. Exp. Biol. and Med., 74, $108(1950)$.

${ }^{2}$ Tamm, I., and Horsfall, F. I., J. Exp. Med., \$5, 71 (1952).

s Werner, I., and Odin, I., Acta Soc. Med. Ups., 57, 230 (1952).

- Blix, G., Svennerholm, I., and Werner, 1., Acta Chem. Scand., B, $358(1052)$

${ }^{5}$ Blix, G., Z. physiol. Chem., 240, 43 (1936).

${ }^{6}$ Gottschalk, A., Nature, 167, 845 (1951).

'Odin, L., Acta Chem. Scand., 5, 1420 (1952).

${ }^{8}$ Odin, L. (unpublished investigations).

- Werner, I. (unpublished investigations).

\section{Indicator Spray for Amino-Acids}

IN quantitative one-dimensional paper chromatography of amino-acids, the position of the various bands is generally determined either by running reference strips on the edges of the paper or by spraying lightly with weak ninhydrin solution. Neither method is entirely satisfactory. Reference strips are not always a reliable guide to cutting, particularly if the bands are close together, since the fronts may not be straight; the use of ninhydrin must give rise to some loss, which will fall most heavily on the acids present in least amount.

In this laboratory, we determine the individual acids manometrically following oxidation, and have developed an indicator spray which shows the position of the bands and does not interfere with the subsequent analysis. The spray consists of an alkaline alcoholic solution of bromothymol blue incorporating formaldehyde, so that, on the principle of the formol titration, the amino-acids appear as acid (yellow) bands against an alkaline (blue) background. The paper gradually fades to a uniform yellow colour ; but the bands can, if necessary, be marked with a ball-point pen for subsequent cutting.

The spray has been used successfully for some time now, generally following a neutral solvent such as propanol-water, so that there is no trouble from residual acidity or alkalinity on the paper which, for quantitative work, is air-dried without application of heat. The spray solution is prepared by adding $3 \mathrm{ml}$. formalin and $0.1 \mathrm{ml} .60$ per cent aqueous potassium hydroxide to $20 \mathrm{ml} .0 \cdot 15$ per cent $(\mathrm{w} / \mathrm{v})$ solution of bromothymol blue in 95 per cent alcohol.

The indicator appears to be almost as sensitive as ninhydrin, particularly for the shorter-chain aminoacids ; but the bands tend to be somewhat narrower, and, when cutting for quantitative work, a little of the paper on either side of the band should be included.

$$
\begin{aligned}
& \text { A. R. KEMBLE } \\
& \text { H. TACPHERSON } \\
& \text { Agricultural Research Council } \\
& \text { Unit of Crop Conservation, } \\
& \text { Department of Chemistry, } \\
& \text { University, Edinburgh. } \\
& \text { July } 2 . \\
& \text { Application of Material in Filter Paper } \\
& \text { Chromatography }
\end{aligned}
$$

\section{Application of Material in Filter Paper Chromatography}

IN order to obtain a good separation in filter papel chromatography, the size of the spot of liquid applied to the paper must be small, which often necessitates repeated, time-consuming applications of material. Methods have been evolved with the purpose of having spots or a. band laid down automatically by a burette ${ }^{1,2}$. There still seems to be a need, however, for a technique by which a larger volume of fluid can be deposited quickly and simply, yet permitting small-sized bands or spots for good separation.

We have used the following procedure. The fluid material is deposited on a strip of filter paper $2-5 \mathrm{~mm}$. in width according to the degree of separation wanted. The filter paper strip, after drying, is placed in a $z$-shaped fold of the filter paper sheet. The size of the fold is slightly larger than the strip (see diagram). In this way the strip carrying the substance to be chromatographed is covered by the filter paper sheet on both sides. The fold is kept closed by the application, on each side of the sheet, of glass rods ground plane on one side or by glass plates of some $5 \mathrm{~mm}$. width and $1.5 \mathrm{~mm}$. thickness. The glass rods or plates are held together on each side of the paper with rubber bands exerting a slight pressure. The filter paper strip should not reach the margin of the sheet but leave $0 \cdot 5-1 \mathrm{~cm}$. on each side.

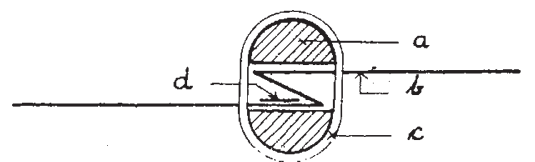
(a) Glass rods ; (b) cross-section of folded filter paper ; (c) mbber
band keeping the fold closed ; (d) filter paper strip carrying the material 